\title{
An in vitro Evaluation of Microleakage of Three Different Self-Etch Adhesives with Ethanol, Acetone and Water as Solvents
}

\author{
S Vijay Singh, Poonam Bogra, Saurabh Gupta, Jyoti Kocchar
}

\begin{abstract}
Purpose: The aim of this study is to evaluate and compare the microleakage of three different self-etch adhesives with ethanol, acetone and water as solvents.

Materials and methods: Standardized class V cavities were prepared on both facial and lingual surfaces of 60 caries-free human premolar teeth. The teeth were divided in three groups and different self-etch adhesives (O ptiBond All in O ne, Tetric $\mathrm{N}$ Self-Etch, Adper Easy One) were applied according to manufacturer's instructions. The samples were then restored with composite and subjected to thermocycling. Later, the teeth were stained with methylene blue, sectioned and measured for microleakage under stereomicroscope.
\end{abstract}

Results: This study showed that at the occlusal margin and gingival margins, the preparations treated with OptiBond all in one showed significantly less leakage than the other groups. Enamel margins provided better marginal sealing than dentin/ cementum margins.

Conclusion: The study demonstrated that O ptiB ond All in One bond had a better sealing ability at both occlusal and gingival margins compared with the other adhesives used.

Keywords: Microleakage, Self-etch adhesives, Solvents.

How to cite this article: Singh SV, Bogra P, G upta S, Kocchar $J$. An in vitro Evaluation of Microleakage of Three Different SelfEtch Adhesives with Ethanol, Acetone and Water as Solvents. Int J Prosthodont Restor Dent 2012;2(3):83-87.

Source of support: Nil

Conflict of interest: None

\section{INTRODUCTION}

The primary aim of dental adhesives is to provide retention to composite fillings or composite cements. In addition to withstanding mechanical forces, and in particular shrinkage stress from the lining composite, a good adhesive al so should be able to prevent leakage along the restoration's margins. Clinically, failure of restorations occurs more of ten due to inadequate sealing, with subsequent discoloration of the cavity margins than due to loss of retention. ${ }^{1}$

Microleakage is defined as the clinically detectable passage of bacteria, fluids, molecules or ions between cavity wall and the restorative materials applied to it. A chieving a micromechanical and biomechanical bond between the restoration and tooth is considered effective and a standard procedure in clinical practice. Therefore, good insights in the components of the adhesives are paramount to understand or even predict their behavior. ${ }^{2}$
The addition of solvents to resins is indispensable to the composition of adhesives that need to bond to dentin. The wet nature of dentin only allows good wetting when a hydrophilic bonding is applied. ${ }^{3}$ The wetting behavior of adhesive is drastically improved by addition of hydrophilic monomers and solvents. ${ }^{4}$ The low viscosity of primers and/ or adhesive resins is partly due to the dissolution of the monomers in a solvent and will improve its diffusion ability in the microretentive tooth surface. In adhesives, water, ethanol and acetone are the most commonly used solvents.

The objective of the present in vitro study is to compare the sealing ability of three different self-etch adhesives with ethanol, acetone and water as solvents.

\section{MATERIALS AND METHODS}

Sixty freshly extracted, caries-free human premolars were kept in distilled water at $4^{\circ} \mathrm{C}$ for 24 hours. Class $V$ cavities were prepared on facial and lingual surfaces, with the gingival margin $1 \mathrm{~mm}$ below the CEJ , using a \#4 round bur with a high speed handpiece and copious amounts of water. The preparations were standardized as $4 \mathrm{~mm}$ long, $3 \mathrm{~mm}$ wide and $2 \mathrm{~mm}$ in depth, and no bevels were placed. The teeth were randomly divided into three groups corresponding to each adhesive system (Table 1). Twenty teeth were assigned to each group and adhesives were applied according to manufacturer's instructions.

The cavities were later restored with resin composite (Charisma, Heraeus K ulzer) and finished using carbide burs. The restored teeth were thermocycled $1000 \times$ at a temperature of $5^{\circ} \mathrm{C}$ and $55^{\circ} \mathrm{C}$. The dwell time was 30 seconds in each water bath, with a transfer time of 30 seconds between each bath. The samples were then blotted dry with a paper towel and the roots were sealed with sticky wax. A $n$ acid-resistant varnish was applied to all surfaces of the teeth except for $1 \mathrm{~mm}$ adjacent to the restoration margins.

The specimens were then subjected to dye leakage tests. They were immersed in 0.5 methylene blue dye solution for 24 hours. A fter staining, the teeth were rinsed in running water and radicular parts of the teeth were cut 4 to $5 \mathrm{~mm}$ below the CEJ. The coronal parts were then sectioned mesiodistally in the approximate center of the restoration with a low-speed diamond saw (Fig. 1).

Two special ists in restorative dentistry (Cohen's K appa 0.74 ) assessed the restorations independently for dye 


\begin{tabular}{|c|c|c|c|}
\hline Groups & Adhesive system & Composition & Manufacturer \\
\hline I & Adper Easy One & $\begin{array}{l}\text { 2-hydroxymethyl methacrylate (HEMA), Bis-GMA, methacrylated } \\
\text { phosphoric esters, } 1,6 \text { hexanediol methacrylate, Vitrebond } \\
\text { copolymer, filler particles, ethanol, water, initiators and stabilizers }\end{array}$ & $\begin{array}{l}\text { Batch\# } 426422 \\
\text { Manufacturer: } 3 \text { M ESPE, } \\
\text { St Paul, MN, USA }\end{array}$ \\
\hline II & Opti-Bond All in One & $\begin{array}{l}\text { Glycerol phosphate dimethacrylate (GPDM), mono-, and } \\
\text { di-functional methacrylate monomers, ethanol, acetone and water } \\
\text { as solvents, photoinitiators, nanofillers and fluoride-releasing fillers }\end{array}$ & $\begin{array}{l}\text { Batch\# } 3332328 \\
\text { Manufacturer: Kerr Co, } \\
\text { Orange, CA, USA }\end{array}$ \\
\hline III & Tetric N-Bond Self-Etch & $\begin{array}{l}\text { Bis-acrylamide derivative, bismethacrylamide dihydrogen phosphate, } \\
\text { amino acid acrylamide, hydroxyalkyl methacrylamide, water, fillers, } \\
\text { initiators and stabilizers }\end{array}$ & $\begin{array}{l}\text { Batch\# N16261 } \\
\text { Manufacturer: Ivoclar } \\
\text { Vivadent, Amherst, NY, USA }\end{array}$ \\
\hline
\end{tabular}

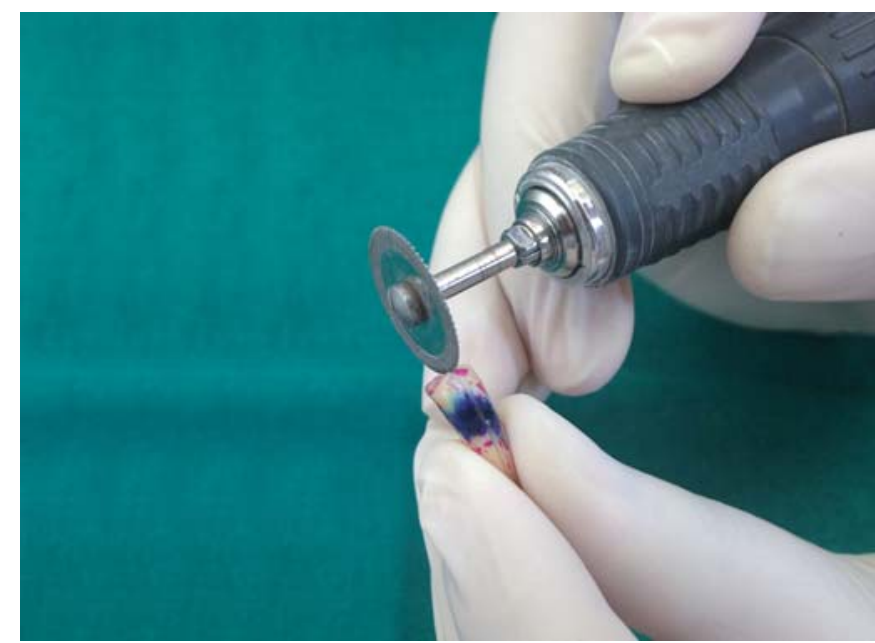

Fig. 1: Sectioning of a tooth with diamond disk

penetration at occlusal and gingival margin using a stereomicroscope $(20 \mathrm{x})$.

Dye penetration using stereomicroscope was done according to following criteria (Fig. 2):

0 - No leakage.

1 - Dye penetration up to one-third of the cavity.

2 - Dye penetration up to two-third of the cavity.

3 - Dye penetration up to full cavity depth.

4 - Dye penetration onto the axial wall of the cavity preparation.

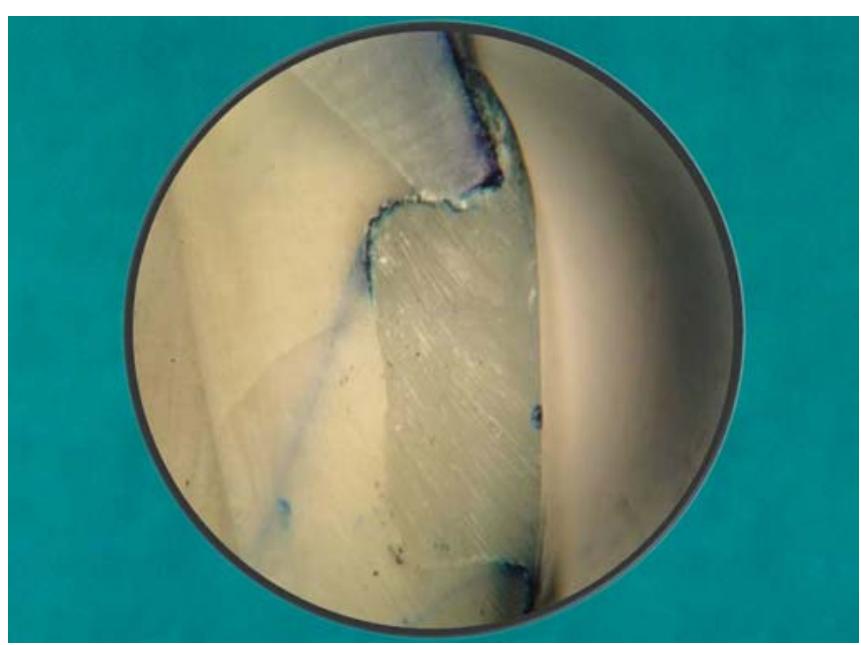

Fig. 2: A score of 4 at occlusal margins and score 1 at gingival margins

\section{RESULTS}

Data were analyzed using nonparametric analysis of variance (A N OV A) (K ruskall-W allis test). B etween group comparisons were made using $M$ ann-W hitney $U$ test and within group comparisons between two locations (occlusal vs gingival) were made using Wilcoxon signed rank test. The confidence of the study was kept at $95 \%$; hence, a p-value less than 0.05 indicated a significant difference.

Dye penetration scores for the occlusal and gingival walls are presented in Table 2.

K ruskal-W allis one-way A N OV A indicated significant differences between groups for occlusal and gingival scores $\left(\chi_{\mathrm{df}=2}^{2}=14.958, \mathrm{p}<0.001, \chi_{\mathrm{df}=2}^{2}=37.989, \mathrm{p}<0.001\right.$, respectively).

The $M$ ann-W hitney test (Table 3 ) was performed to evaluate significant differences of occlusal and gingival scores between groups. The results demonstrated no significant leakage differences among A dper Easy One and OptiB ond All in One. Conversely, Tetric N Self-Etch had significantly more dye penetration when compared to A dper Easy $O$ ne and $O$ ptiB ond $A l l$ in One.

Gingival scores between groups showed some significant differences: Tetric N Self-Etch showed significantly more dye penetration when compared to A dper Easy One and $O$ ptiB ond All in One.

When comparing the occlusal and gingival scores for each group, the Wilcoxon rank test (Table 4) showed the mean microleakage at occlusal location was significantly lower as compared to that at gingival location in all the three groups.

\section{DISCUSSION}

Solvents are substances that are capable of dissolving or dispersing one or more other substances. When a solvent dissolves a solid or a liquid, the molecules (or ions) become separated from each other and the spaces in between become occupied by solvent molecules. The energy required to break the bonds between solute molecules is supplied by the formation of bonds between the solute particles and the solvent molecules: the old intermolecular forces are replaced 
An in vitro Evaluation of Microleakage of Three Different Self-Etch Adhesives with Ethanol, Acetone and Water as Solvents

Table 2: Dye penetration scores at coronal and gingival margins (Kruskal-Wallis test)

\begin{tabular}{|c|c|c|c|c|c|c|c|}
\hline & 0 & 1 & 2 & 3 & 4 & Mean & Standard deviation \\
\hline \multicolumn{8}{|l|}{ Coronal } \\
\hline Adper Easy One & 24 & 13 & 3 & 0 & 0 & 0.475 & 0.640 \\
\hline OptiBond All in One & 26 & 14 & 0 & 0 & 0 & 0.350 & 0.483 \\
\hline Tetric N Self-Etch & 12 & 19 & 9 & 0 & 0 & 0.925 & 0.730 \\
\hline \multicolumn{8}{|l|}{ Gingival } \\
\hline Adper Easy One & 9 & 14 & 10 & 3 & 4 & 1.475 & 1.219 \\
\hline OptiB ond All in One & 12 & 16 & 8 & 2 & 2 & 1.150 & 1.075 \\
\hline Tetric N S elf-Etch & 0 & 1 & 19 & 11 & 9 & 2.700 & 0.853 \\
\hline
\end{tabular}

Table 3: Mann-Whitney test to evaluate differences between groups

\begin{tabular}{llcccccr}
\hline S.no. & Comparison & \multicolumn{3}{c}{ Coronal } & & \multicolumn{3}{c}{ Gingival } \\
\cline { 3 - 4 } \cline { 6 - 8 } & & Mean difference & z-value & p-value & Mean diff. & z-value & $p$-value \\
\hline 1. & Adper Easy vs OptiBond All in One & 0.125 & 0.693 & 0.488 & 0.325 & 1.216 & 0.224 \\
2. & Adper Easy vs Tetric N & -0.450 & 2.832 & 0.005 & -1.225 & 4.673 & $<0.001$ \\
3. & OptiBond All in One vs Tetric N & -0.575 & 3.642 & $<0.001$ & -1.550 & 5.810 & $<0.001$ \\
\hline
\end{tabular}

Table 4: Microleakage at coronal vs gingival locations (Wilcoxon signed rank test)

\begin{tabular}{llcc}
\hline S. no. & Group & z-value & p-value \\
\hline 1. & Adper Easy & 5.122 & $<0.001$ \\
2. & OptiBond All in One & 4.815 & $<0.001$ \\
3. & Tetric N & 5.857 & $<0.001$ \\
\hline
\end{tabular}

by new ones. The solubility characteristics of molecules are determined chiefly by their polarity. ${ }^{5}$

Chemists have classified solvents into three categories according to their polarity: polar protic, dipolar aprotic and apolar solvents. Polar protic solvents consist of a hydroxylgroup that can form strong hydrogen bonds. Examples are water and ethanol. Polar aprotic solvents do not have the required hydroxyl-group to form hydrogen bonds but do have a large dipole moment. They usually also contain a ketone group. Typical example is acetone. A polar solvents have both a low dielectric constant and dipole moment.

In adhesives, water, ethanol and acetone are the most commonly used solvents (Table 5). Other polyval ent alcohol solvents have been evaluated but are not used commercially. ${ }^{6}$ The use of these organic solvents in adhesives must be explained by their inexpensiveness, their wide availability and their good biocompatibility. M ost important characteristics of a solvent are its dipole moment, dielectric constant, boiling point, vapor pressure and $\mathrm{H}$-bonding capacity. The vapor pressure of a solvent is important to ensure good evaporation of the solvent after application of the adhesive onto tooth tissue. ${ }^{7,8}$ Remaining solvent in the adhesive may jeopardize polymerization due to dilution of the monomers and may result in voids and hence permeability of the adhesive layer. ${ }^{9,10}$

The results showed that at both occlusal and gingival margins group II (OptiB ond All in One) exhibited lowest microleakage than the other bonding systems, follow ed by Adper Easy One and Tetric N Self-Etch.

$O$ ptiB ond All in One contains a unique combination of ternary solvents that is ethanol, acetone and water. Ethanol is a polar solvent that forms hydrogen bonds with its solutes. Its high vapor pressure as compared to water allows better evaporation by air drying. Ethanol when used in conjunction with water forms an 'azeotropic mixture'. This implies the formation of hydrogen bonds between water and ethanol molecules, resulting in a better evaporation of these waterethanol aggregates than pure water. Self-evidently, this results in more water removal from the adhesive and lesser chances of void formation. ${ }^{5,11}$

The high vapor pressure of acetone, which is four times that of ethanol, is a main advantage. It facilitates better evaporation by air-drying. Similar to ethanol, acetone and water make an azeotrope. It has a very good water removing capacity, because of its high dipole moment and excellent evaporation capacities. ${ }^{12}$ This is often referred to as the 'water-chasing' capacity of acetone. ${ }^{13}$

Table 5: Main characteristics of solvents used in adhesives

\begin{tabular}{lcccc} 
Solvent & $\begin{array}{c}\text { Dipole moment in gaseous } \\
\text { state in Debye at } 25^{\circ} \mathrm{C}\end{array}$ & $\begin{array}{c}\text { Dielectric constant at } 293^{\circ} \mathrm{K} \\
\left(20^{\circ} \mathrm{C}\right)\end{array}$ & $\begin{array}{c}\text { Boiling temperature }\left({ }^{\circ} \mathrm{C}\right) \\
\text { Vapor pressure in } \mathrm{mm} \mathrm{Hg} \\
\text { at } 25^{\circ} \mathrm{C}\end{array}$ \\
\hline Water & 1.85 & 80 & 100 & 23.8 \\
Acetone & 1.69 & 24.3 & 78.5 & 54.1 \\
Ethanol & 2.88 & 20.7 & 56.2 & 200 \\
\hline
\end{tabular}


Also, the filled adhesive technology of OptiB ond All in One, i.e., the presence of a nanofiller and fluoride-releasing filler ensures the higher level of protection against microleakage.

A dper Easy One also contains ethanol and water as solvents which explain for its comparatively lesser microleakage than Tetric $\mathrm{N}$ self-etch, which contains only water as the solvent. The high boiling temperature and low vapor pressure of water imply that this solvent is difficult to remove from adhesive solutions after application on the tooth. In addition, the equilibrium of water between fluid and gaseous state is also in favor of the fluid state, which will decrease the rate of evaporation even more. ${ }^{14}$ Tay et al, ${ }^{15}$ showed that excess water in the adhesive resin compromises with the marginal adaptation due to entrapment of water blisters resulting in overwet phenomenon.

The presence of a specific polyalkenoic copolymer$\checkmark$ itrebond also plays a significant role in the inferior performance of Adper Easy One when compared to $O$ ptiB ond All in One. The rationale for the use of this polymer was to provide better moisture stability. However, several authors demonstrated that this monomer does not dissolve in the adhesive's solution, leading to a separate phase producing many globules within the polymer of the adhesive layer, thus compromising with its marginal adaptation. ${ }^{16,17}$

The results also showed that the microleakage at the enamel margins is less as compared to that of the microleakage at the dentin/cementum margins. This difference can be explained by the composition of these two tissues which is very different. Dentin is a wet tissue and contains more water than enamel and this water interferes with the adhesive particles. These ones can penetrate the dentin only if they are hydrophilic. The formation of smear layer at the surface of the dentin, after the use of burs, blocks dentinal tubules and prevents all direct contact of any material with the dentinal substrate. The bond obtained in this situation is insufficient and fragile, with much higher possibilities for microleakage.

\section{CONCLUSION}

Dental adhesives are intricate mixtures of ingredients. Profound knowledge of these ingredients is one key to better understanding the behavior of adhesives in studies and in clinic. Good understanding also provides better insights in the correct clinical use of adhesives. Each ingredient has to some extent a specific effect on the microleakage, bonding efficiency, bonding durability, shelf life and biocompatibility of the adhesive system. In addition, ingredients may affect each other in a complicated interplay of factors. Unbalanced mixtures of ingredients may lead to reduced bonding effectiveness, sealing ability, durability and to phase-separation reactions, while a well thoughtout formulation will be the key to long-term clinical success.

\section{REFERENCES}

1. V an Landyut $K L$, Snauwaert J, De M unck J, Peumans $M$, Y oshida Y, Poitevin A. Systematic review of the chemical composition of contemporary dental adhesives. Biomaterials 2007; 28:3757-785.

2. M edic V, Obradovic-Djuricic K, Dodic S, Petrovic R. In vitro evaluation of microleakage of various types of dental cements. Srp Arh Celok Lek 2010;138(3-4):143-49.

3. Watanabe I, Nakabayashi N, Pashley DH. Bonding to ground dentin by a phenyl-P self etching primer. J Dent Res $1994 ; 73(6): 1212-20$.

4. Tay FR, Pashley DH. Have dentin adhesives become too hydrophilic? J Can Dent A ssoc 2003;69(11):726-31.

5. M orrison RT, B oyd RN. Organic chemistry. B oston: Allyn and Bacon 1973.

6. Ohhashi M, Chigira H, Itoh K, Hisamitsu H, Wakumoto S. Effects of polyval ent al cohol solutions as dentin primers. J D ent 1997; 25(2):161-66.

7. A bate PF, Rodriguez VI, M acchi RL. Evaporation of solvent in one-bottle adhesives. J D ent 2000;28(6):437-40.

8. Ikeda T, De M unck J, Shirai K, Hikita K, Inoue S, Sano H, et al. Effect of evaporation of primer components on ultimate tensile strengths of primer-adhesive mixture. Dent $M$ ater 2005;21(11):1051-58.

9. Hotta $\mathrm{M}, \mathrm{K}$ ondoh $\mathrm{K}, \mathrm{K}$ amemizu $\mathrm{H}$. Effect of primers on bonding agent polymerization. J Oral Rehab 1998;25(10):792-99.

10. Hashimoto $M$, Ito $S$, Tay FR, Svizero NR, Sano H, Kaga M, et al. Fluid movement across the resin-dentin interface during and after bonding. J Dent Res 2004;83(11):843-48.

11. Moszner $N$, Salz U, Zimmermann J. Chemical aspects of selfetching enamel-dentin adhesives: A systematic review. Dent M ater 2005;21(10):895-910.

12. A bate PF, Rodriguez VI, M acchi RL. Evaporation of solvent in one-bottle adhesives. J D ent 2000;28(6):437-40.

13. Jacobsen $T$, Soderholm KJ. Some effects of water on dentin bonding. Dent M ater 1995;11(2):132-36.

14. Pashley EL, Zhang Y, L ockwood PE, Rueggeberg FA, Pashley DH. Effects of HEM A on water evaporation from water-HEM A mixtures. Dent M ater 1998;14(1):6-10.

15. Tay FR, Gwinnett JA, W ei SH. Relation between water content in acetone/al cohol-based primer and interfacial ultrastructure. J Dent1998;26(2):147-56.

16. Spencer $P, W$ ang $Y$, W alker M P, W ieliczka D M , Swafford JR. Interfacial chemistry of the dentin/adhesive bond. J Dent Res 2000;79(7):1458-63.

17. V an M eerbeek B, Conn J L L , Duke ES, Eick JD, Robinson SJ, Guerrero D. Correlative transmission electron microscopy examination of nondemineralized and demineralized resin-dentin interfaces formed by two dentin adhesive systems. J Dent Res 1996;75(3):879-88. 


\section{ABOUT THE AUTHORS}

\section{S Vijay Singh (Corresponding Author)}

Professor and Head, Department of Conservative Dentistry and Endodontics, DAV D ental College, Y amuna Nagar, Haryana, India e-mail: drvijay_endo@ rediffmail.com

\section{Poonam Bogra}

Professor, Department of Conservative Dentistry and Endodontics DA V Dental College, Y amuna Nagar, H aryana, India

\section{Saurabh Gupta}

Professor, Department of Conservative Dentistry and Endodontics DA V D ental College, Y amuna Nagar, Haryana, India

\section{Jyoti Kocchar}

Postgraduate Student, Department of Conservative Dentistry and Endodontics, DAV Dental College, Y amuna Nagar, Haryana India 